\title{
Creating a More Globally Conscious Classroom
}

\author{
Andrew Nowlan \\ Kwansei Gakuin University, Japan \\ nowlan1979@yahoo.com
}

\begin{abstract}
With knowledge of English being considered a basic requirement for success on the world stage, many English language educators neglect to teach intercultural competence (IC) in the process, often to the detriment of the student. After attempting to define culture, teaching goals will be outlined based on the five elements of IC as outlined by Byram (2000, para. 8). For each element, tasks and activities will be suggested that can be used in most intermediate and advanced language classes, regardless of geographic area. All tasks are designed to utilize authentic material and experiences which will help language students take the necessary steps in becoming global citizens.
\end{abstract}

While students may contest that they are not interested in studying the culture of every global region, the instructor must stress that the world today is not as segregated by boundaries and borders as it was before. "The contemporary world is marked by dwindling space, shrinking time, and disappearing borders, resulting in an unprecedented flow not only of economic capital and consumer goods, but also of cultural values across the world" (Kumaravadivelu, 2008, p. 147). Bearing this in mind, one must consider that business meetings in multicultural cities such as Singapore, Hong Kong, or Dubai may consist of members hailing from North and Latin America, Europe, the Middle East, Africa, Australia and elsewhere throughout the world. A broad understanding of global cultures will give graduates of a language program the proper background to apply their language skills effectively.

Language classes across the globe are becoming more communicative, but many students still hesitate to use their communication skills in cross-cultural situations. One of the reasons for this is due to the lack of IC taught in the classroom. If language students increase their awareness of other cultures (C2), learning motivation can increase, leading to a greater understanding of both language skills and their own culture (C1).

The process of applying world culture could be considered a daunting task by many instructors. However, this paper will outline strategies that can be applied to a curriculum involving culturally homogenous or multicultural classes. While the exercises mentioned are more suitable for intermediate to advanced-level students, beginner students could still benefit by the teacher scaling down and simplifying the approach.

\section{Defining Culture and Intercultural Competence}

Most English instructors have an interest in creating a more globally conscious classroom, but many of them will have problems in developing a clear-cut definition of culture. One should not be discouraged from teaching culture due to an inability to clearly define it. Culture is such

Language Education in Asia, 2010, 1(1), 147-157. http://dx.doi.org/10.5746/LEiA/10/V1/A13/Nowlan 
an ambiguous term that asking ten people to define it will usually result in ten different definitions. In early attempts to define the word, some scholars went as far as claiming culture to be "one of the two or three most complicated words in the English language" (Williams, 1976, p. 87). Adjectives often associated with defining culture include elusive, unclear, notorious, and impossible.

To help delineate the meaning of culture, several definitions were considered, though only one will be used for the purpose of this paper. Scollon and Scollon (2001, p. 139) stress the need to differentiate between high culture and anthropological culture. While high culture is concerned with intellectual and artistic endeavors, Scollon and Scollon argue that the field of intercultural competence is more concerned with anthropological culture. This type of culture is reflected in worldviews, customs, language, social organizations and the day-to-day practices that characterize one group from another. This paper focuses on the study and application of anthropological culture, though students can benefit through examination of high culture as will be seen in the activities section of this paper.

Cultural capital, a term developed by French sociologist Pierre Bourdieu (1986), refers to intellectual and educational assets achieved through socialization and schooling. Compared to other forms of capital (economic and social), cultural capital involves forms of knowledge that will give one a higher status in society. When the learner reaches a point of accumulating enough cultural capital, it becomes possible to apply this knowledge in cross-cultural situations, thus becoming interculturally competent. In his work on cultural globalization,

Kumaravadivelu (2008) presents Byram's 1997 classification of a person possessing a degree of intercultural competence:

someone who can operate their linguistic competence and their sociolinguistic awareness of the relationship between language and the context in which it is used, in order to manage interaction across cultural boundaries, to anticipate misunderstandings caused by difference in values, meanings and beliefs, and thirdly, to cope with the affective as well as cognitive demands of engagement with otherness. (as cited in Kumaravadivelu, p. 133)

Language training and IC training should go hand-in-hand. Despite efforts to motivate students to study English, many students are unable to fully appreciate why they should learn a language that they may never use in the future. If this is the case, it becomes the responsibility of the teacher to motivate the students by highlighting the opportunities that become available with English language acquisition. If language lessons are complemented with IC training, students will be able to see the correlation between learning language and having success with world travel, study abroad programs, making foreign friends, and working for international organizations. Students with minimal or no interest in these opportunities can benefit from IC training by gaining a greater understanding and appreciation of $\mathrm{C} 1$.

The next section of this paper will present ideas for activities that will help students achieve IC. Activities will be given in a sequential order based on Byram's (2000) five elements of IC.

\section{Five Components of Intercultural Competence}

Becoming interculturally competent is not an overnight process, but instead a series of steps that take time to accomplish, each step building upon the skills and attitudes achieved through completion of previous elements. The five components of IC conceived by Byram (2000, para. 8) make for well-defined course objectives for any teacher interested in creating a more culturally-conscious classroom. These five elements are: 

1. Attitudes
2. Knowledge
3. Interpreting and Relating
4. Discovery and Interaction
5. Critical Cultural Awareness/Political Education

It is proposed in this paper that each element can be taught and reinforced through three stages:

1) State the overall objective of the element and introduce language. For example, when teaching the first lesson on attitudes, vocabulary such as stereotype and prejudice can be introduced.

2) Share an authentic experience, observation, or belief about a culture that clearly contributes to the value of learning the element. This experience should effectively present the cultural issue or problem. If teaching about stereotypes (attitudes), a personal experience of when the instructor was victim of a stereotype in the host culture can be shared. It helps understanding if the situations shared are both interesting and relevant to students. Experiences can be provided by the teacher, students, or found online.

3) Provide thought-provoking questions and activities that will give students an opportunity to use the target language within a culturally stimulating environment inside and outside the classroom. Discussion questions based on video clips (e.g., selections from www.youtube.com) can be particularly valuable as students will improve listening skills through exposure to different varieties of English. For example, the instructor can show clips featuring Indian, Singaporean, Australian, and British speakers using English. Followup questions can be used about the clip that focus both on content and the variety of English used.

To maximize student participation and ensure interest throughout the IC training, the instructor should perform a needs assessment to gauge the existing level of intercultural competence amongst the students. This needs assessment should ask students about experiences abroad and cross-cultural situations in which they may have been involved. General interests and attitudes toward learning IC should also be identified to ensure that materials can be gathered for the target audience. Common interests for university students include relationships, music, festivals, food, and fashion. If the instructor can successfully take a familiar subject and present unfamiliar and interesting aspects with a global perspective, students will more readily digest and retain the content.

Task summaries for each element, with a sequence of tasks that a practicing teacher may use to help reinforce lesson goals, are given in Appendix A.

Element 1: Attitudes. Especially for people with limited experience abroad, it can give comfort to classify a group of people from one particular region or culture into a mold that can be applied to any single person within that group. This leads to stereotyping. For an educator hoping to create a more culturally sensitive class, this is one of the first and most important challenges to overcome before moving on to activities where students are asked to assess foreign cultures. A stereotype can be defined as "a fixed, frozen, and often false image we retain about an individual or a group of individuals" (Kumaravadivelu, 2008, p. 50). Language educators must help students evolve from the attitude that "cultural difference is cultural 
deficiency" (Kumaravadivelu, 2008, p. 88) as this ultimately leads to the establishment of stereotypes.

The goal and overall objective of this first element is for students to become curious, openminded, and flexible about other cultures. Key language should be introduced in this early stage. Teachers can decide what vocabulary to cover, depending on the skill level of their students. Regardless of level or ability, terms such as stereotype and prejudice should be presented, even if it simply acts as review for more advanced students.

It is effective to use authentic experiences in the classroom to help exemplify the overall learning goal. These can be based on the instructor's experiences or those from students, acquaintances, or even online sources. For each experience, the instructor must be sure to engage students in critical thinking before exposing them to the material. In this sample situation, students can be asked to identify stereotypes that may have been present during this cross-cultural exchange:

On the second day living with my host family, I was told that we would be having Chinese food. I like eating Chinese food but I was curious to know how an American family would prepare and eat it, food I eat in East Asia, and more surprisingly, everyone in the family could use chopsticks very well! I was impressed by their ability to do this.

After giving students some time to brainstorm in small groups, it usually becomes clear that the visitor held two stereotypes of American people. The first misconception is that Americans are unable to use chopsticks and the second is that Americans only eat hamburgers and hot dogs. By identifying exceptions to the stereotype, students can begin to see that generalizations of a society cannot be applied to individuals.

After following the aforementioned stages of 1 ) introducing the objective (open-mindedness) and language (stereotype and prejudice), and 2) sharing a real-world example, activities can then be introduced that will reinforce the overall goal. One possible task involves having students develop a list of stereotypes one group of people may have of another, then having students identify exceptions and falsehoods of each stereotype. For example, if the stereotype that women are bad drivers is used, identifying the achievements of the female American race car driver Danica Patrick quickly debunks this claim. If the instructor has difficulties thinking of genuine examples, an Internet search involving the country or group in question plus the word stereotype will produce much material that can applied to teaching this element. If video clips from a site such as www.youtube.com are used, a simple search of the country or group in question plus the word stereotype will also provide valuable listening clips. If the instructor chooses to do this, level-appropriateness must be a consideration.

Upon completion of activities related to the attitudes element, students will hopefully realize how stereotypes develop and how stereotypes ultimately act as a barrier to truly understanding culture.

Element 2: Knowledge. "[If someone has Internet access,] whether a kid in Cambodia, the university professor, or me who runs a search engine, all have the same basic access to overall research information that anyone has. It is a total equalizer" (Friedman, 2005, p. 178). The cofounder of Google, Sergey Brin, made this statement while commenting on the information age that we are currently in. We live in an era where someone with Internet access is empowered with seemingly endless resources for researching any given subject. In his statement, Brin does 
not account for the vast discrepancy in Internet access worldwide, but the implication of this statement for teachers is this: If Internet access is available, take advantage of it.

The Internet remains the most powerful tool for completing the objectives of the second element in Byram's (2000) five-step path to IC. The knowledge element involves studying the products, practices, and interactions of another culture with the final goal of building awareness and understanding of that other culture. When drawing on an authentic experience, it makes for a more stimulating discussion if an example is given where a lack of cross-cultural understanding is demonstrated. Before sharing an experience that the teacher feels is interesting and relevant to students, pre-reading questions should be provided to ensure that the students think critically. For example, the instructor may have students consider 1) why was there a problem? 2) how could it have been solved?

About a month after I moved to Tokyo, I had plans to meet a group of Japanese colleagues for dinner. We planned to meet outside Shibuya Station at 8 p.m. I arrived at 8:15. This is common practice in my home country, but I felt as if my friends here were annoyed with my tardiness. This made me feel guilty.

After brainstorming in small groups, students should be able to identify the cultural problem as a mismatch in conceptions of time. In regions of the world where time is flexible, such as Cambodia, students are given a chance to fully understand how it may feel to be tardy for a social engagement in Japan. With resulting negative sentiments such as guilt and embarrassment, students can begin to identify the importance of IC, as someone fluent in a foreign language, but untrained in IC, can easily be tripped up by cultural customs.

After reviewing the learning objective, presenting difficult language items, and discussing the authentic experience, instructors have myriad activities at their disposal to help compensate for a lack of knowledge on culture. After looking at the sample experience (e.g., tardiness in Japan), the class could segue naturally into a discussion on cross-cultural mistakes and solutions. Role plays could be set up (in this case, what to do when running late for a social or business gathering). Role plays of other culturally unique situations could be used, for instance, tipping in North America. Moreover, teachers could divide classes into small groups to research and present a country to the class, with the students taking the roles of travel agents. Presentations can also focus on such topics as C2 places, individuals, history, ways of living, music, art, or literature. With a focus on online material, teachers and students are both encouraged to search for material.

Administering tasks designed to help increase awareness and understanding of other cultures is the second step to becoming IC. Upon completion of this step, students should come to realize that they cannot operate in our globalized society with the belief that their worldview is the only acceptable option. Students will fully harness this knowledge when they begin to interpret a C2 event from the point of view of their own culture. This is the focus of the next element.

Element 3: Skills of Interpreting and Relating. To fully transition student impressions of C2 from acceptance to true understanding, an effort must be made by the instructor to help students identify links between $\mathrm{C} 1$ and C2 when analyzing different cultures. If this connection can be made and if students are able to interpret a cultural event or object from $\mathrm{C} 2$ in relation to $\mathrm{C} 1$, students will begin to realize that seemingly vast cultural differences are really not so extreme. The most significant and perhaps ironic benefit of covering this element is that the student will begin to have revelations about their own culture through better understanding other cultures. 
As this is the third of five IC elements outlined by Byram (2000), teachers should consider reflecting on what has been learned and assimilated in the first two elements. An effective strategy to both review and advance the curriculum is to present a cross-cultural event from the perspective of someone who has neglected to consider the first two elements of attitudes and knowledge. Pre-reading questions can be given for such a situation, including 1 ) why did this person feel shocked? 2) why did this happen to the person? 3) what could have been the outcome had the person embraced appropriate attitude and knowledge?

I was visiting Phnom Penh in mid-April and was enjoying the sights of the city wearing a great new outfit that I had bought at the Russian Market. I was on the sidewalk looking at my map when all of a sudden two young men drenched me with ice-cold water and spread talcum powder all over my face. I was too shocked to get angry or upset. What did I do to deserve this treatment?

After reading the previous testimony, any Cambodian would be able to identify that this person was not victim to indiscriminate or discriminate assault, but instead was simply being encouraged by the locals to take part in Chaul Chnam, the Khmer New Year festival (Saunders, 2008, p. 56). This festival, also celebrated in other Southeast Asian countries, involves throwing cold water and colored talc at people for three days in what is considered by many as a noisy and tumultuous event. While foreigners may look at these rituals as strange or abnormal, the third element of IC asks students to interpret their own festivals through the eyes of a foreigner. If North Americans can begin to see the oddities of Halloween, Spaniards of the Running of the Bulls and La Tomatina, and Irish of St. Patrick's Day (green beer?), then the third element of IC (interpreting and relating) can be considered as assimilated.

As globalization continually acts to blur borders and shrink time and space, the instructor is responsible for having students reflect on this phenomenon and how it has impacted the $\mathrm{C} 1$. This can be a difficult task when teaching younger students who are convinced that McDonald's restaurants are from the students' home country, even if that happens to be Japan, Thailand, or Brazil. Students should be asked the key questions of 1) how has globalization impacted the $\mathrm{C} 1$ ? and 2) what $\mathrm{C} 1$ exports are making an impact abroad? Answering these questions will help illustrate that globalization is a two-way street. A general understanding of the forces of globalization will help students in more advanced activities such as comparing the customs and cultural items of $\mathrm{C} 1$ and $\mathrm{C} 2$. Also, students can do a show and tell where they first describe a cultural item or event from $\mathrm{C} 1$ followed by an item or event from $\mathrm{C} 2$. Doing this consecutively will allow students to see $\mathrm{C} 1$ and C2 in a new light, which will in turn help build a bridge of understanding between two customs that at first seem very different.

After this third element is studied and understood, students can begin to consider how to use their language skills to help advance their knowledge of $\mathrm{C} 2$ and increase IC. This will be examined throughout the fourth element.

Element 4: Skills of Discovery and Interaction. "The overall objective of culture teaching is to help L2 learners develop the ability to use the target language in culturally appropriate ways for the specific purpose of empathizing and interacting with native speakers of the target language" (Kumaravadivelu, 2008, p. 114). If one were to agree with Kumaravadivelu here, then it would be well-received news to both the instructor and students that completion of this fourth element represents the pinnacle of IC training. Through the study of this element, students are expected to build confidence and comfort in acquiring new knowledge of a C2 and its practices through interaction in real-time. This environment is difficult to simulate in the classroom, but the instructor is in a position to give students the necessary tools needed to 
successfully meet this objective. An authentic experience can be relayed that will demonstrate how a person with high IC can reap cultural capital from a culturally confusing situation. This time, it is important to stress that the following situation illustrates a person who has studied and assimilated the first three elements of IC.

I was stuck in a traffic jam because of a large demonstration outside Seoul City Hall. I noticed one sign read "No Free Trade." I had read about the likely occurrence of protests in Korea but was still surprised by the large size of the demonstration and the anger of the people who took part. Later that day, I kindly asked the hotel staff about the earlier protest. They laughed and warmly shared their supporting views of free trade. Like people in every country, including mine, Koreans don't all think alike.

Through a positive, educated, and well-informed approach, this person was able to ask questions to a neutral party about a seemingly controversial topic to find out that the harsh feelings witnessed were not felt by all people in Korea. Because of the high degree of IC operating in this situation, the writer was able to conclude that disagreements exist amongst members of a community and that this is standard in most communities around the world. One must keep in mind that within any apparent community, there are issues that will polarize and cause conflict. Examples of such issues in the USA include abortion, gun rights, and gay marriage.

Class activities that can prepare students for cross-cultural interactions in the real-world include debate, discussing the root of and solutions to world problems, writing letters of complaint or opinion to governments or companies, or listening to arguments while having students defend one side or the other. During these activities, it is vital that students not lose sight of the first element, attitude. In debating or discussing a conflict, students should hone their listening and analytical skills by seeing both sides of a situation. Students can try to defend a point of view that they do not actually support or make a case to the class about why they love something they actually hate. Fostering a positive, open-minded attitude will facilitate the acquisition of new cultural capital under the constraints of real-time. Instructors can, if possible, encourage guest speakers from abroad to visit the classroom and have students interact with the guest through questions and impromptu conversation. Exchange students are ideal for this.

If an appropriate amount of time is dedicated to the first four elements and if material chosen by the instructor is considered both interesting and relevant by the students, the fifth and final component of IC can be achieved independently.

Element 5: Critical Cultural Awareness/Political Education. Similar to language, culture is dynamic and ever changing. For example, since 9/11 in New York City, many Americans have a different worldview and a premium has been placed on security. Any traumatic event in a person's life will impact how that person perceives the world. This can alter the everyday practices of that individual or the society as a whole. The fifth element of IC aims at developing the ability to critically evaluate perspectives, practices, products, and politics of C1 and C2. Furthermore, the interculturally competent citizens of the world should be able to recognize what constitutes appropriate in a given situation and they should have a continual interest in and awareness of the ever-changing global village.

Becoming and remaining interculturally competent is a process that requires constant and continual research, inquiry, and self-reflection. Teachers and educators of IC should be in a state of constant exposure to cultural change and should not become complacent with the 
knowledge and resources that exist at their disposal. In his 2009 study, Aubrey challenges instructors of culture to step outside their immediate communities and comfort zones in order to acquire the opinions and logic of those in different living environments (Aubrey, 2009, p. 120). This is sound advice as teachers often forget that they, in addition to students, are responsible for learning.

\section{Conclusion}

Having students perform the tasks described in this paper will not only develop intercultural competence, but also language competence. Through this training, students will be exposed to new vocabulary and sentence structures, as well as world issues. Most activities can be done individually or in small groups, so this type of training is appropriate for any class size. The development of intercultural competence will build comfort and confidence in students when interacting with foreigners. Students may also become more at ease with communicating in English after they are exposed to the different types of non-native English varieties that exist around the world. When presenting new vocabulary and C2, students will need to practice their communication skills in order to negotiate meaning with classmates. Listening skills will be enhanced by asking students to interpret sound clips of native and nonnative English speakers around the world describing their cultures. Finally, instructors should make use of newspapers, magazines and Internet articles to help foster an interest in reading about other regions of the world.

The main challenge for instructors teaching IC is to create a learning environment conducive to the sharing of ideas and experiences. Teachers must see themselves not only as facilitators of cultural instruction, but also as cultural ambassadors and "brokers between cultures of all kinds" (Kumaravadivelu, 2008, p. 134), especially those teaching a class of students from different cultural backgrounds. Regardless of creed, race, gender, or nationality, all language educators should be aware of their unique role in influencing the current and next generation of learners who will participate in this increasingly globalized society.

Instructors must keep in mind that in any classroom, there is potential for resistance to change and open-mindedness. Some students may interpret the study of foreign culture as a threat to their own cultural identities. While the average language learner is also interested in cultural acquisition, there are those who may feel threatened or uncomfortable with exposure to different cultures and ways of living. For this reason, it is important to format a needs analysis before developing a sophisticated IC curriculum. This needs analysis should include questions such as Are you interested in learning about international culture? What foreign culture have you been exposed to in the past? What region of the world are you most interested in studying? and What cultural differences are you interested in exploring?

Instructors thinking of applying culture in the classroom are urged to consider students' language level to maximize the benefits of cross-cultural study; advanced students will be able to process and analyze more sophisticated issues while beginner to intermediate students should be exposed more to issues they are already familiar with. If www.youtube.com clips are used in class to help teach a point, it is important that material and language used in the clip is level-appropriate. Regardless of language level, an IC curriculum can involve an intensive approach where consecutive classes are dedicated to meeting the goals of the first four elements. Alternatively, the instructor can take an approach that gradually integrates the application of culture into the curriculum with the intention of covering as many IC components as class time restrictions allow. For example, if time is limited, the instructor could assign students to do a short show-and-tell on a cultural event from C1 (element 3). This would act as a precursor to examining and presenting similar cultural events from C2. For example, if 
a Cambodian student presents the Chaul Chnam festival, the student could follow it up with a presentation on the Japanese bean-throwing festival that signifies the start of a new season. While throwing beans may seem like a strange tradition at first, students will reflect on the peculiarities of $\mathrm{C} 1$ to better interpret this $\mathrm{C} 2$ event.

Covering only one or two of the five elements will introduce the outside world to students and possibly generate curiosity and interest; however, students will only become truly conscious of other cultures, and ultimately their own, if all five elements are learned and practiced.

"Learning about other cultures may lead to cultural literacy; it is learning from other cultures that will lead to cultural liberty" (Kumaravadivelu, 2008, p. 237).

\section{Biodata}

Andrew Nowlan is a language instructor at Kwansei Gakuin University near Osaka, Japan. He has experience in teaching English throughout East Asia. Originally from Halifax, Canada, Andrew has traveled the world extensively and is interested in the application of intercultural communication and World Englishes in the classroom.

\section{References}

Aubrey, S. (2009). Creating a global cultural consciousness in a Japanese EFL classroom. CCSE English Language Teaching, 2(2), 119-131.

Bourdieu, P. (1986). The forms of capital. In J. G. Richardson (Ed.), Handbook of theory and research for the sociology of education, pp. 241-258. New York, NY: Greenwood Press.

Byram, M. (1997). Teaching and assessing intercultural communicative competence. London, UK: Multilingual Matters.

Byram, M. (2000). Assessing intercultural competence in language teaching. Sprogforum, 6(18), 8-13. Retrieved from http://inet.dpb.dpu.dk/infodok/sprogforum/Espr18/byram.html

Friedman, T. L. (2005). The world is flat: A brief history of the twenty-first century. New York, NY: Farrar, Straus and Giroux.

Kumaravadivelu, B. (2008). Cultural globalization and language education. New Haven, CT: Yale University Press.

Saunders, G. (2008). Culture smart! Cambodia: The essential guide to customs \& culture. London, England: Kuperard.

Scollon, R., \& Scollon, S. W. (2001). Intercultural communication. Malden, MA: Blackwell.

Williams, R. (1976). Keywords: A vocabulary of culture and society. Oxford, England: Oxford University Press. 


\section{Appendix A \\ Task Summaries}

Although the activities in the following task summaries are presented as steps, the instructor should keep in mind that these tasks can be performed in any order that seems suitable for the audience.

\section{Element 1 Task Summary}

Step 1: Present the goal (e.g., realizing how stereotypes develop and how they act as a barrier to truly understanding culture).

Step 2: Present pertinent language related to the element (e.g., stereotype, prejudice, bias, discrimination).

Step 3: Present experiences (e.g., Chinese food in America) and have students identify existing stereotypes.

Step 4: Have students identify stereotypes that people have of a particular group (women, Cambodians, Americans, senior citizens, etc.) and ask students to come up with exceptions to each stereotype.

Step 5: Present stereotypes that foreigners may have of the $\mathrm{C} 1$ and ask students to find exceptions and inconsistencies with these stereotypes.

Step 6: Reinforce listening skills related to the topic through www.youtube.com clips and ask questions related to the attitudes expressed.

\section{Element 2 Task Summary}

Step 1: Present the goal, in this case, realizing that knowledge acquisition is critical in becoming more open-minded about the worldviews and cultural practices that exist.

Step 2: Present vocabulary related to cross-cultural misunderstandings e.g., guilty, embarrassed, stressed, etc.

Step 3: Provide an example situation where a visitor to country lacks cross cultural understanding.

Step 4: Have students identify the mistakes made by the visitor in the example and how the conflict could have been avoided.

Step 5: Examine other situations that lead to cross-cultural misunderstandings and have students identify the problems and solutions. Examples include tipping customs in North America, taking off shoes in Japan, conservative dress in Cambodia, etc.

Step 6: Role play situations where cross-cultural misunderstandings could exist. Dialogues could be developed by the instructor or found online.

Step 7: Assign groups of students a particular country or world region to research online. Information to search is up to the instructor, but can include a country's language, religion, holidays, climate, food, sports, etc. A more advanced class can research attitudes towards various issues.

\section{Element 3 Task Summary}

Step 1: Present the goal, in this case, building a bridge of understanding between C1 and C2.

Step 2: Review principles from first two elements encouraging open mindedness and research.

Step 3: Present a situation of C2 that might seem strange to the students at first (e.g., the Chaul Chnam festival).

Step 4: As questions relating to the event.

Step 5: Find equivalents of the C2 event in C1 (e.g., comparing holiday rituals).

Step 6: Introduce the word globalization.

Step 7: Compare C1 imports and exports and discuss the impact this has on the local and foreign culture. 


\section{Element 4 Task Summary}

Step 1: Present the goal, in this case, building comfort and confidence in acquiring C2 knowledge through interactions in real time.

Step 2: Present an example when a visitor to a country was able to overcome a culturally confusing event by exercising IC skills (e.g., protests in Korea).

Step 3: Ask students to identify the process involved with overcoming the problem.

Step 4: Discuss issues that polarize a population within particular borders (e.g., abortion, gun control, immigration).

Step 5: To help students maintain a positive attitude when interacting with foreigners, practice debate, especially having students defend positions they do not necessarily believe in.

Step 6: If accessible, ask exchange students or foreigners to visit the classroom for a culturally related discussion. 